\title{
Design gráfico e subjetividades: os significados intangíveis presentes na informação visual de anúncios publicitários de perfumes femininos Graphic design and subjectivities: the intangible meanings present in the visual information of advertisements for women's perfumes
}

\author{
Felipe Machado de Souza \& Francisco A. P. Fialho
}

consumo, pós-modernidade, subjetivação, expressão visual

\begin{abstract}
O consumo na pós-modernidade não prolifera somente bens e serviços mas, também, todos os predicados intangíveis atribuídos e associados a eles. Entretanto, uma empresa não concede imaterialidade as suas mercadorias se essas não nos afetarem. Sem estabelecer uma mediação física perceptível - com os sujeitos, os significados não são recebidos e, consequentemente, não são incorporados aos bens e serviços. Logo, as empresas precisam de estratégias comunicacionais como, por exemplo, os anúncios publicitários. Esses, em grande parte, são elaborados pelos designers gráficos. Eles criam, selecionam e organizam elementos visuais, que combinados em uma superfície qualquer, transmitem informações significativas e emocionais relativas à uma marca ou produto - cooperando para a construção da imaterialidade. Em outras palavras, o design gráfico materializa o intangível ao traduzir o imaterial em expressões tangíveis, visuais. Esse estudo, a partir de uma pesquisa visual, de caráter exploratório e qualitativo, buscou verificar como os significados intangíveis contidos nas informações visuais de diferentes peças publicitárias de perfumes femininos impactaram os participantes da pesquisa. O estudo evidenciou que os anúncios publicitários, decorrentes dos projetos e das atividades de design gráfico, que controlam e organizam os elementos visuais perceptíveis, propiciaram impressões e sensações subjetivas específicas nos entrevistados cooperando com a lógica do processo de subjetivação do consumo pós-moderno.
\end{abstract}

consumption, postmodernity, subjectivation, visual expression

Consumption in postmodernity does not only proliferate goods and services but also all intangible predicates attributed and associated with them. However, a company does not grant immateriality to its merchandise if it does not affect us. Without establishing a sensible - physical mediation - with the subjects, the meanings are not received and, consequently, are not attributed to the goods and services. Therefore, companies need communication strategies, such as commercials. These, to a large extent, are elaborated by graphic designers. They create, select and organize visual elements that, combined on any surface, convey meaningful and emotional information about a brand or product - cooperating for the construction of the intangible. Graphic design materializes the intangible by translating the immaterial into tangible, visual expressions. This study, based on a visual exploratory and qualitative research, seeks to verify how the intangible meanings contained in the visual information of different advertising pieces of women perfumes impacted the research participants. The study evidenced that advertisements, resulting from projects and graphic design activities, which control and organize the perceptible visual elements, provided specific impressions and subjective feelings in the interviewees, cooperating with the logic of the subjectivation process of postmodern consumption.

\section{Introdução}

$\mathrm{Na}$ atualidade, podemos dizer que o 'produto não vale pelo seu uso, mas pelo desejo e, principalmente, pelo coeficiente de fantasia que nele se corporifica' (Santaella, 2016, p. 7). Cada vez mais, consumimos bens e serviços pelos seus predicados intangíveis atribuídos e associados a eles pelas corporações (Semprini, 2010; Serroy \& Lipovetsky, 2015). Esta lógica, instituída na pós-modernidade possibilitou um universo de significados no qual as mercadorias, muito além da materialidade, adquiriram um sentido imaterial, um vetor de projeção.

\author{
Anais do 9 CIDI e 9 CONGIC \\ Luciane Maria Fadel, Carla Spinillo, Anderson Horta, \\ Cristina Portugal (orgs.) \\ Sociedade Brasileira de Design da Informação - SBDI \\ Belo Horizonte | Brasil | 2019 \\ ISBN 978-85-212-1728-2
}

Proceedings of the 9th CIDI and 9th CONGIC

Luciane Maria Fadel, Carla Spinillo, Anderson Horta,

Cristina Portugal (orgs.)

Sociedade Brasileira de Design da Informação - SBDI

Belo Horizonte | Brazil | 2019

ISBN 978-85-212-1728-2 
Os bens e serviços, mais do que entidades objetivas, transformaram-se em entidades subjetivas (Moraes, 2010). As mercadorias foram transferidas ao mundo das experiências, dos desejos e das emoções (Campbell \& Barbosa, 2006). Para adentrar esse mundo, as corporações precisam usufruir, muitas vezes, das modalidades de comunicação como a publicidade e o design gráfico, consideradas grandes responsáveis pela disseminação e produção dos conteúdos, pelas mensagens e pelas simbologias que os bens e serviços adquirem no mercado competitivo (Souza, 2018).

As peças publicitárias, por exemplo, que na maioria das vezes são elaboradas pelos designers gráficos, são capazes de intermediar as propriedades físicas das marcas, bens e serviços - que estão no mundo real - e as propriedades afetivo-simbólicas - que constituem nossas subjetividades. Por meio de combinações variadas, porém categóricas, de sinais e elementos gráfico-visuais, o design gráfico cria diferentes associações, interpretações e significados com o objetivo de que determinado bem ou serviço evoque um conjunto de emoções e sentimentos específicos (Souza, 2018). Por tais razões, podemos dizer que a informação visual presente em uma peça publicitária transmite significados atrelados à uma marca e, além disso, influencia e estimula experiências subjetivas e emocionais. Portanto, designers podem, por meio do controle e organização de aparatos gráfico-visuais persuasivos, estimular sensações e impressões singulares nos indivíduos.

Para verificar a hipótese levantada, a partir de uma pesquisa exploratória, demonstramos que a informação gráfico-visual presente em peças publicitárias estáticas de perfumes femininos causaram impressões e sensações específicas nos participantes de uma pesquisa visual. Titonni (2008) afirma que as pesquisas com recursos imagéticos são relevantes para compreender subjetividades; portanto, o estudo ${ }^{1}$ serviu para entender como os sujeitos deram sentidos conotativos, isto é, subjetivos, as informações contidas nos anúncios de perfumes femininos aos quais foram expostos. Com os resultados da coleta de dados organizados, observamos, empiricamente, que 1) o conjunto de sensações e impressões causadas pelas imagens publicitárias foram diferentes entre elas 2) Cada um dos anúncios causou, individualmente, em grande parte dos participantes, as mesmas sensações e sentimentos. Logo, o estudo evidenciou que os anúncios publicitários, decorrentes dos projetos e das atividades de design gráfico, que controlam e organizam os elementos visuais perceptíveis, propiciaram sensações e impressões subjetivas cooperando com a lógica do consumo pósmoderno.

\section{Consumo e subjetividade}

Segundo Gobé (2010), nos dias de hoje, são os dilemas inconscientes e emocionais que mobilizam o sistema de consumo. Os desejos, os encantamentos, as expressões pessoais e a procura de sentidos que tem dado suporte à produção e ao ciclo capitalista. Em suma, 'já não é a funcionalidade fria que está na ordem do dia, mas a atratividade sensível e emocional' (Lipovestky, 2007, p. 39). Essa lógica passou a funcionar, principalmente, a partir do momento em que 'a consciência foi retirada de seu lugar destacado no psiquismo e relativizada em relação ao inconsciente' (Birman, 2003, p. 61). Como resultado, conforme explana Cunha (2007), os desejos ganharam o centro da cena, tornando a fantasia e as emoções uma potência na produção de efeitos concretos sobre a subjetividade. A verdade sobre o sujeito já não encontra correspondência ou possibilidade de verificação na dita realidade material, acessível ao Eu consciente. Mas, surge, muitas vezes, de modo inesperado e enigmático num emaranhado de fantasias compostas por traços psíquicos impregnados de emotividade.

A constituição e expressão da identidade do sujeito pós-moderno concentram-se nas preferências, realizações e gostos pessoais, relacionados às experiências subjetivas (Campbell \& Barbosa, 2006). Essa nova maneira de nos relacionarmos com o mundo externo e material influencia diretamente em como consumimos e atribuímos significado aos produtos. Para Semprini (2010) e Serroy e Lipovetsky (2015), o que se consome hoje são as ideias, as

\footnotetext{
${ }^{1}$ O presente trabalho foi realizado com apoio da Coordenação de Aperfeiçoamento de Pessoal de Nível Superior Brasil (CAPES) - Código de Financiamento 001. Os autores fazem parte do grupo de pesquisa Significação da Marca, Informação e Comunicação Organizacional - SIGMO/UFSC.
} 
imagens, os prazeres estéticos, as fantasias e os valores impregnados e associados aos bens e serviços. Por meio da aquisição e do uso de um produto encantado, repleto de significado intangível e afetivo, passamos a acessar e, ao mesmo tempo, externalizar nossos conteúdos psicológicos. Em outras palavras, consumimos aquilo que de outro modo seria inacessível, inconsciente, mas que, por meio das mercadorias, ganha materialidade; o fenômeno do fetichismo mercadológico (Canevacci, 2001). Logo, bem-estar, feminilidade, virilidade, poder, sensualidade, sofisticação, felicidade, mistério, realização, superação, sabedoria, transgressão, inocência, independência etc. são corporificados nos bens e serviços e oferecidos a nós nas prateleiras das lojas e vitrines de shoppings. Cada vez mais, passamos a consumir não apenas os produtos, mas antes de tudo, os predicados intangíveis embutidos nesses produtos, que também são adquirimos nos atos de compra (Souza, 2018).

Os produtos tornarem-se símbolos que falam aos sentimentos e emoções (Martins, 2007; Perez, 2016). Estas características do consumo pós-moderno, em razão da relevância da emoção e do simbólico que o constitui, entram em ressonância particular com a dialética da marca (Semprini, 2010). Elas são, muitas vezes, quem produzem as fantasias e os imaginários que organizam o sistema de consumo, existindo com potência no campo subjetivo.

As marcas ganharam aspectos intangíveis, além dos aspectos tangíveis que já a constituíam. Sendo assim, por um lado, elas encontram-se no mundo físico, onde se concretizam por meio de aspectos sensoriais e materiais que caracterizam seus produtos. Aqui, a marca leva em conta toda a sua expressividade e sua identidade. Por outro, elas existem no mundo psicológico, onde se transferem ao campo dos símbolos e afetos. Nesse âmbito, as marcas são definidas pelas sensações e impressões que provocam nos consumidores, suas imagens mentais (Perassi, 2001).

As marcas, produtos e serviços estão presentes e são oferecidos no mundo físico. No mundo mental, estão as experiências e percepções relacionadas à marca, decorrentes da interação dos indivíduos com o mundo físico. Estas se originam da conversão das percepções e relações diretas com o mundo físico em sensações, experiências e emoções. Esta interiorização dá origem às imagens mentais. As imagens mentais aparecem e reaparecem na consciência a partir de estímulos, que podem ser originários do mundo físico, como a percepção de um produto ou de uma publicidade (Schmiegelow, 2016, p. 45).

Uma marca não consegue conceder significados intangíveis às suas mercadorias se essas não chegarem às mentes dos indivíduos. Sem estabelecer uma mediação física - perceptível com as pessoas, os significados não são recebidos e, consequentemente, não são internalizados nem atribuídos aos bens e serviços. Por essa razão, as marcas precisam das modalidades de comunicação. O consumo é moldado e definido de acordo com os significados simbólicos e culturais que são atribuídos e transferidos pelas estratégias comunicacionais das marcas aos produtos e, em seguida, deles para a mente dos consumidores (McCracken, 2003).

As estratégias comunicacionais, como explica Canevacci (2001), são quem animizam e subjetivizam as mercadorias. Elas substanciam e deslocam os significados do mundo culturalmente constituído em direção a um produto; e desse produto para os sujeitos (McCracken, 2003; Campos, 2013). Podemos dizer, apoiados nas teorias de Souza (2018) e McCracken (2003), que fazem parte das estratégias comunicacionais: a publicidade, a propaganda, a fotografia, o design, o design gráfico, as relações públicas, as ferramentas de marketing, dentre outros. No presente artigo focaremos, especificamente, o Design Gráfico, que em conjunto com a publicidade, une o mundo real (propriedades físicas e reais) e o mundo psicológico (propriedades imaginárias e simbólicas) das marcas. A materialidade dos produtos, por meio da significação elaborada pela comunicação visual publicitária, proporciona a circulação dos significados das mercadorias e, ainda, tangibiliza nossos anseios psicológicos (Souza, 2018). Não fossem o design gráfico e a publicidade os produtos seriam percebidos como commodities. Afinal, ambos materializam e disseminam as fantasias e os encantamentos instituídos nos produtos, garantindo que as marcas participem dos processos de subjetivação.

\section{Design gráfico de anúncios publicitários}

'É a publicidade que se responsabiliza pela captação e expressão, quase sempre subliminar, 
dos valores que se agregam às mercadorias' (Santaella, 2016, p. 8). Mas a publicidade não age sozinha no deslocamento do significado cultural, ela precisa de diversas outras áreas para conseguir a transferência em toda sua completude - dentre uma delas está o design gráfico. Na perspectiva de Newark (2009) e Hollis (2005), a publicidade e o design gráfico são inseparáveis. Ambos são 'inquestionavelmente da mesma família, assim como a poesia e a ficção são ambos literatura' (Newark, 2009, p. 22).

A publicidade não existe sem anúncios de comunicação publicitária e, na maioria das vezes, segundo Campos (2013), os designers gráficos são os responsáveis pela atividade projetual desses anúncios. Eles atuam 'como diretor de arte, supervisionando a fotografia ou outros materiais ilustrativos encomendados' (Hollis, 2005, p. 2). Portanto, quem substancia e planeja o(s) significado(s), por meio da decisão dos códigos-objetos que serão utilizados na expressão da propaganda das marcas e produtos, é o designer gráfico. Ele orquestra as imagens visuais com o intuito de transmitir uma mensagem emocional e intangível que se pretende incutir na mente dos consumidores. As imagens visuais são elementos centrais dos projetos gráficos e têm papeis relevantes no deslocamento dos significados do mundo para o objeto. McCracken (2003) explana que as imagens visuais parecem assumir uma relação muito particular no processo de transferência do significado. É principalmente o aspecto visual da propaganda que conjuga o mundo e o objeto, elementos entre os quais busca-se fazer a transferência de significado.

Enquanto os publicitários atem-se à promoção e a mensagem de um produto ou marca, os designers gráficos, em geral, além de darem forma, organizam e articulam as expressões da comunicação. Sendo assim, enquanto a dimensão inteligível - que lida com as informações no plano de conteúdo - é destinada à publicidade; a dimensão sensorial é destinada às atividades do design gráfico - que toma como base o plano da expressão, organizando um conjunto de sinais físicos (Campos, 2013).

A publicidade atua como potente método de transferência de significado, fundindo um bem de consumo a uma representação do mundo culturalmente constituído dentro dos moldes de um anúncio específico. O diretor de arte [design gráfico] de uma agência busca conjugar esses dois elementos de tal modo que o espectador/leitor vislumbre uma similaridade essencial entre eles. Quando está equivalência simbólica é estabelecida com sucesso, o espectador/leitor atribui ao bem de consumo propriedades que ele ou ela sabe que existem no mundo culturalmente constituído (McCracken, 2003, p. 107).

Na publicidade o design gráfico tem função persuasiva pois concebe, programa, projeta e realiza comunicações visuais destinadas a transmitir mensagens específicas a grupos determinados (Frascara, 2001). Por essa razão, ele se caracteriza como uma especialidade do design que desenvolve projetos amplamente caracterizados pela manipulação de imagens persuasivas.

Para que as imagens persuasivas funcionem em toda a sua amplitude, o Design Gráfico considera sempre os aspectos culturais, sociais e econômicos dos auditórios - as sociedades às quais os enunciados são dirigidos - e faz uso de aparatos gráficos que permeiem, traduzam e sintetizem necessidades e anseios e desejos de uma sociedade (Junior \& Nojima, 2010, p. 13).

O designer gráfico cria e seleciona sinais e elementos visuais persuasivos, que combinados em uma superfície qualquer, transmitem informações significativas relativas à uma marca, bem ou serviço - cooperando com a construção de um significado intangível. O designer gráfico dá sentido ao seu material mediando-o através de códigos da linguagem visual. Esse profissional é alguém que transforma o mundo e o que nele acontece em signos e imagens, podendo fazer visível o invisível. Ele está em toda parte, explicando, informando, expressando, identificando impondo um significado a tudo (Newark, 2009).

Sendo assim, o design gráfico orquestra não apenas os aspectos objetivos da comunicação como também atribui sentido aos elementos, participando de maneira ativa na construção dos significados do mundo culturalmente constituído. O trabalho dos designers, portanto, 'os torna embaixadores entre as empresas e o mercado, a ligação que cria a linguagem da beleza e das emoções', sendo considerados, portanto, 'provocadores conceituais' (Gobé, 2002, p. 12). 


\section{Procedimentos metodológicos}

O estudo utilizou o que Loizos (2013) denominou de pesquisa visual. Este tipo de pesquisa usufrui de imagens como fonte de dados para estudar um fenômeno social (Collier, 1973). A pesquisa visual revela-se importante no processo de construção do conhecimento, especialmente, quando o fenômeno a ser compreendido trata de subjetividades (Reis, 2010). Titonni (2008) vê o recurso imagético como um método eficaz para estudos que tematizam processos de subjetivação.

A pesquisa visual ocorreu com 48 participantes; eles foram orientados a escrever individualmente, para todos os anúncios publicitários de perfume feminino ao qual foram expostos, entre cinco a oito palavras ou expressões, para cada um deles. Essas, por sua vez, deveriam traduzir e expressar os anúncios, contendo as principais impressões e sentimentos provocados/evocados pelos elementos visuais. Embora na pesquisa visual original ${ }^{2}$ tenhamos exposto 12 campanhas de perfumes femininos, no presente artigo, discorreremos apenas dois deles: J'adore e Miss Dior Chérie, amdos da marca Dior.

Por tratar-se de uma pesquisa visual utilizou-se, para a interpretação dos dados, leituras denotativas e conotativas. Inicialmente, efetuamos uma leitura denotativa (ou objetiva), que consiste em descrever o significado literal, a definição (Batey, 2010). De acordo com Hall (2016), o sentido denotativo é o nível simples, básico, descritivo, em que o consenso é difundido e a maioria das pessoas concordaria no significado.

Já a leitura conotativa (ou subjetiva), consiste na interpretação de uma imagem de acordo com o repertório de cada interpretante. Em vista disso, permite leituras mais singulares. No nível conotativo, somos capazes de decodificar sentidos e temas ligados a campos semânticos mais vastos como "elegância", "formalidade", "romance" etc. (Hall, 2016). O significado conotativo é mais variável, figurado e subjetivo. Ele inclui os sentimentos e emoções que uma palavra ou imagem evoca nas pessoas e as associações pessoais e socioculturais que delas surgem (Batey, 2010).

$\mathrm{Na}$ discussão dos resultados apresentaremos tanto as leituras denotativas quanto as leituras conotativas das imagens publicitárias de perfumes femininos. Porém, vale enfatizar, que as conotações foram baseadas nos sentidos dados pelos 48 participantes da pesquisa visual. Para melhor entendimento dos significados subjetivos e imateriais concebidos aos anúncios, o estudo apresenta uma nuvem de palavras, com todas as expressões mencionadas, para cada um deles.

Foi utilizado uma ferramenta online que produz nuvem de palavras, o wordart. O objetivo das nuvens foi organizar e destacar as informações com base no número de menções feitas em determinado texto, hierarquizando.

\section{Discussão dos resultados}

A partir do controle de imagens persuasivas e outros elementos gráficos perceptíveis, os designers supervisionam as fotografias, as ilustrações e os formatos; determinam pesos, ênfases de certos componentes, cores, tipos, enfim, planejam as informações e expressões sensoriais das peças publicitárias para que provoquem determinadas emoções e sentimentos, subjetivando-nos.

São os designers gráficos que definem, de modo altamente planejado, como as propriedades do produto (gráfico, digital etc.) serão apresentadas fisicamente. Esses profissionais unem os significados intangíveis e simbólicos definidos pelos publicitários e estrategistas aos produtos com os sinais e convenções perceptíveis. Em outras palavras, eles contribuem para a materialização da intangibilidade das mercadorias porque traduzem o imaterial em expressões tangíveis, visuais. Os designers gráficos são responsáveis pelas

\footnotetext{
${ }^{2}$ Souza, F. M. (2018). Marcas, mitos e subjetividades: os arquétipos das deusas gregas expressos em imagens publicitárias contemporâneas. Dissertação de Mestrado, Universidade Federal de Santa Catarina, Florianópolis, SC, Brasil.
} 
impressões desencadeadas em nossa psique, já que orquestram e organizam a dimensão sensorial, os conjuntos de sinais físicos (Souza, 2018).

A seguir apresentaremos duas análises de anúncios publicitários de perfumes femininos e como as informações gráficas contidas nas imagens foram significadas pelos participantes da pesquisa. A escolha da categoria de perfumes foi estratégica já que, segundo Perez (2016) e Randazzo (1996), ela é dominada pelo imaterial. Os perfumes não são apenas uma substância para atribuir "cheiros agradáveis" às pessoas; na verdade, os perfumes vendem sensações e experiências intangíveis, significando os indivíduos. Isso porque, concretizam seus significados por meio de expressões sensíveis (Perez, 2016).

\section{Miss Dior Chérie}

Por meio da leitura denotativa da peça publicitária do Miss Dior Chérie, podemos descrever uma jovem posicionada no centro do anúncio; seu braço direito, encontra-se estendido segurando balões de ar. Os balões, que ocupam a maior parte do anúncio, possuem tamanhos e cores diferentes (tons pastéis). O outro braço da modelo segura um frasco do perfume, sendo que a embalagem do produto aparece novamente em proporções aumentadas, no canto inferior direito da imagem. A cor do conteúdo do frasco é um verde pastel. A moça está usando um vestido curto, rodado e cor-de-rosa; porém, não é justo, por isso, não marca a cintura nem as demais partes do corpo. Seus sapatos também são cor-de-rosa, numa tonalidade mais clara que o vestido, com o desenho do estilo "boneca". A moça olha para a direção do leitor da imagem e não está sorrindo. Ao fundo, observamos Paris. A cidade pode ser reconhecida facilmente graças à Torre Eiffel. É dia e o céu está azul claro. Há poucas nuvens. Parte do nome do perfume, Miss Dior, está escrito com uma fita de cetim rosa bebê em frente aos balões. É um estilo tipográfico manuscrito, assim como o restante do nome, Chérie, que embora não tenha sido escrito com a fita de tecido, também é uma fonte manuscrita.

Figura 1: Anúncio publicitário do perfume Miss Dior Chérie, Dior. Fonte: www.fragrantica.com.br (2017).

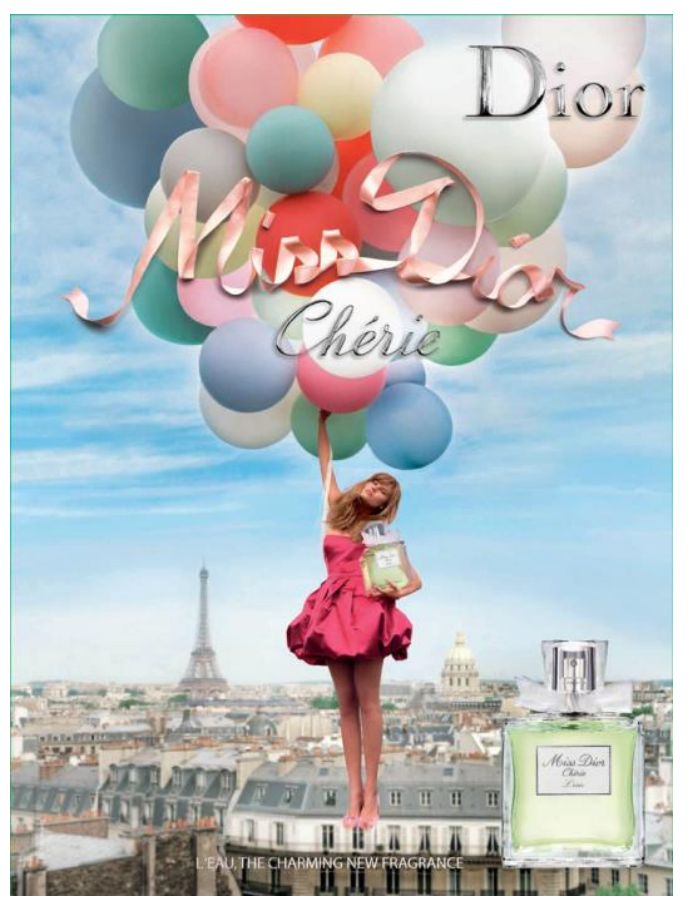

Os elementos visuais dessa peça publicitária evocaram significações e impressões bastante similares na leitura conotativa. As informações expressivas que substanciam a comunicação deste produto, ou seja, a materialidade dada pelo design gráfico à publicidade do perfume, são conotados com a infância e a juventude conforme observamos por meio do levantamento de 
dados da pesquisa visual (Figura 2). Diversas palavras e termos utilizados pelos participantes para traduzir essa imagem pertencem ao mundo "não-adulto": lúdico, infantil, jovialidade, boneca, teen, ingenuidade, infantilização, inocência, alegre, alegria, fantasia, menininha, menina, jovem, delicado, delicadeza, pureza, Lolita, pueril, romântica, romance, romantismo, perfeitinha, brincadeira, adolescente, sonhadora, suavidade, sonho, juventude, brincar, divertido, diversão, descoberta, feliz, doçura etc.

Figura 2: Nuvem de palavras com as expressões usadas para o anúncio do Miss Dior Chérie. Fonte: Dados da pesquisa (2017).

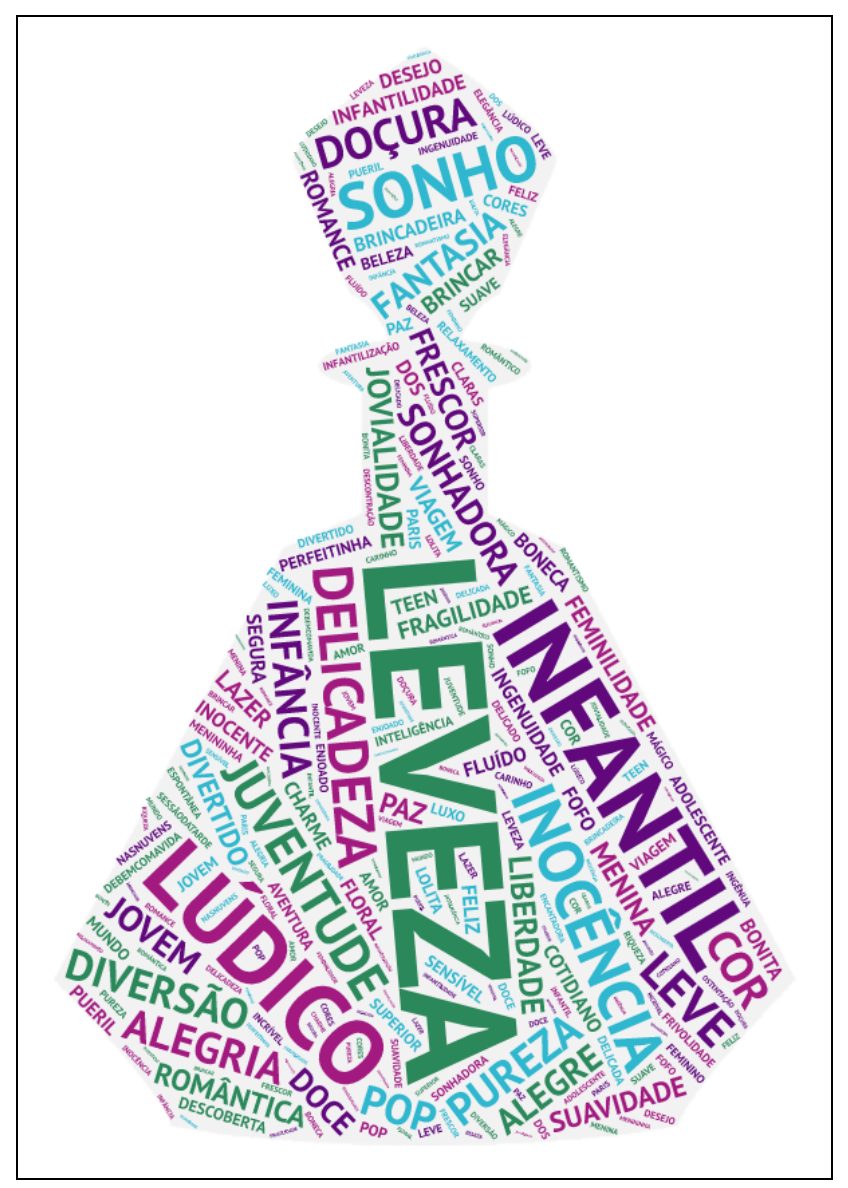

Os 20 primeiros significados utilizados - aqueles que a imagem despertou com maior força nas subjetividades dos participantes - somaram 145 palavras. Vale lembrar que, ao total, foram usadas 222 expressões para traduzir essa imagem. Notamos que o sentido dado pelos 20 primeiros termos, que são a maioria, é muito similar. A representação feminina deste anúncio remete ao arquétipo do feminino infantil. Notamos que do segundo ao vigésimo termo mais recorrente há uma grande relação conotativa. Todas possuem uma similaridade na significação, pois pertencem e se associam ao mundo infanto-juvenil.

\section{J'adore}

O anúncio publicitário do perfume J'adore (Figura 3), novamente da Dior, mostra, em primeiro plano, uma jovem mulher loira de cabelos relativamente curtos e ondulados (Charlize Theron). Seu corpo não aparece inteiro no enquadramento da imagem publicitária, pois ela foi cortada da cintura para cima (Meio Primeiro Plano). O ombro esquerdo encontra-se de frente para o leitor e o direito voltado para o fundo da imagem, ou seja, a mulher está posicionada quase que em perspectiva lateral. A expressão corporal não permite vermos o braço direito, mas, notamos que a mão desse braço toca a parte superior do seio direito, bastante similar ao detalhe da pintura O nascimento de Vênus, de Botticelli. A mão do braço esquerdo, entretanto, 
parece estar apoiada sobre a cintura, já que o braço indica tal movimento. O rosto da mulher está levemente virado e os olhos, semicerrados, encaram o leitor. O enquadramento não nos dá certeza, mas ela parece usar um vestido marrom, sendo que uma das alças do vestido cai sobre o braço esquerdo, aquele que indica a mão na cintura. No fundo, atrás dela, vemos o que parece ser um grande lustre. Ele está em segundo plano e desfocado; provavelmente, em outro cômodo do cenário, pois há uma abertura de porta entre a mulher e o lustre.

Neste anúncio, há uma predominância da cor dourada, inclusive, o próprio frasco do perfume, que também está no primeiro plano da imagem, é dourado. O vidro do perfume possui um formato similar a uma gota e está do lado esquerdo da imagem. O nome do produto, J'adore, está em caixa baixa, com alternação no alinhamento das letras. Isto é, a linha de base não é a mesma para todas as letras, algumas estão um pouco acima da linha e outras abaixo. A marca-gráfica da empresa Dior, localiza-se logo abaixo do nome do perfume, porém, com a linha de base ordenada.

Figura 3: Anúncio publicitário do perfume J'adore, Dior. Fonte: www.fragrantica.com.br (2017).

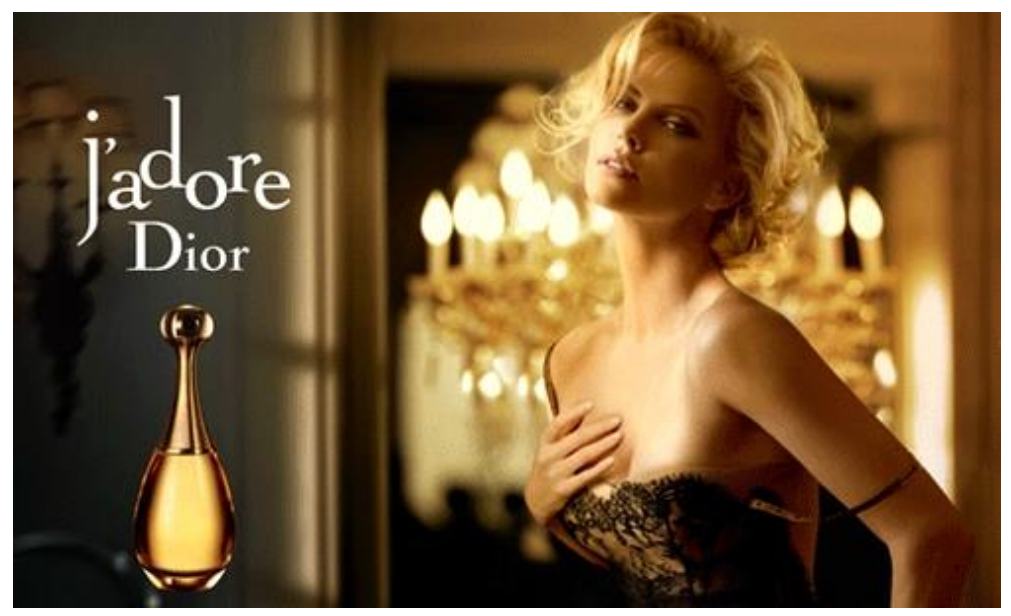

Podemos afirmar que, dentre os anúncios de perfumes expostos na pesquisa visual, o J'adore é, indubitavelmente, o que mais evoca e traduz sensualidade, sedução e beleza. Embora alguns outros anúncios publicitários da pesquisa também tenham auferido essas palavras; este, diante dos demais, teve, além da maior frequência dessas associações, uma ordenação das palavras escritas pelos participantes bastante similar.

Quanto a frequência na pesquisa visual, sedução, sensualidade e beleza totalizaram 70 das palavras mais utilizadas para traduzir a imagem - sendo que a soma de todas, das três e das demais, resulta em 229. Sedução obteve 30 frequências; sensualidade, 25; e beleza, 15; ocupando, respectivamente, a primeira, a segunda e a quarta posição. Ou seja, somadas elas representam a maior parte das impressões e sensações conotativas causadas nos participantes pelo anúncio publicitário do J'adore. Podemos observar que as informações gráficas contidas no anúncio são relativas ao conceito intangível de sensualidade e sedução.

Outras palavras que surgiram com menor frequência reforçam esses sentidos anteriores, são elas: sexy, tentação, charme, amante, malícia, quente, atração, paixão, deusa, deleite, perfeição, fatal, desejo, sexo, prazer, conquista, dominatrix, erotismo, irresistível e provocante/provocativo. Juntas esses demais termos conservam o sentido de sedução, sensualidade e beleza e somam mais 46 palavras ao núcleo dessa significação. Ou seja, somente neste contexto obtivemos 116 palavras; mais da metade de todas as utilizadas para traduzir a imagem publicitária. 


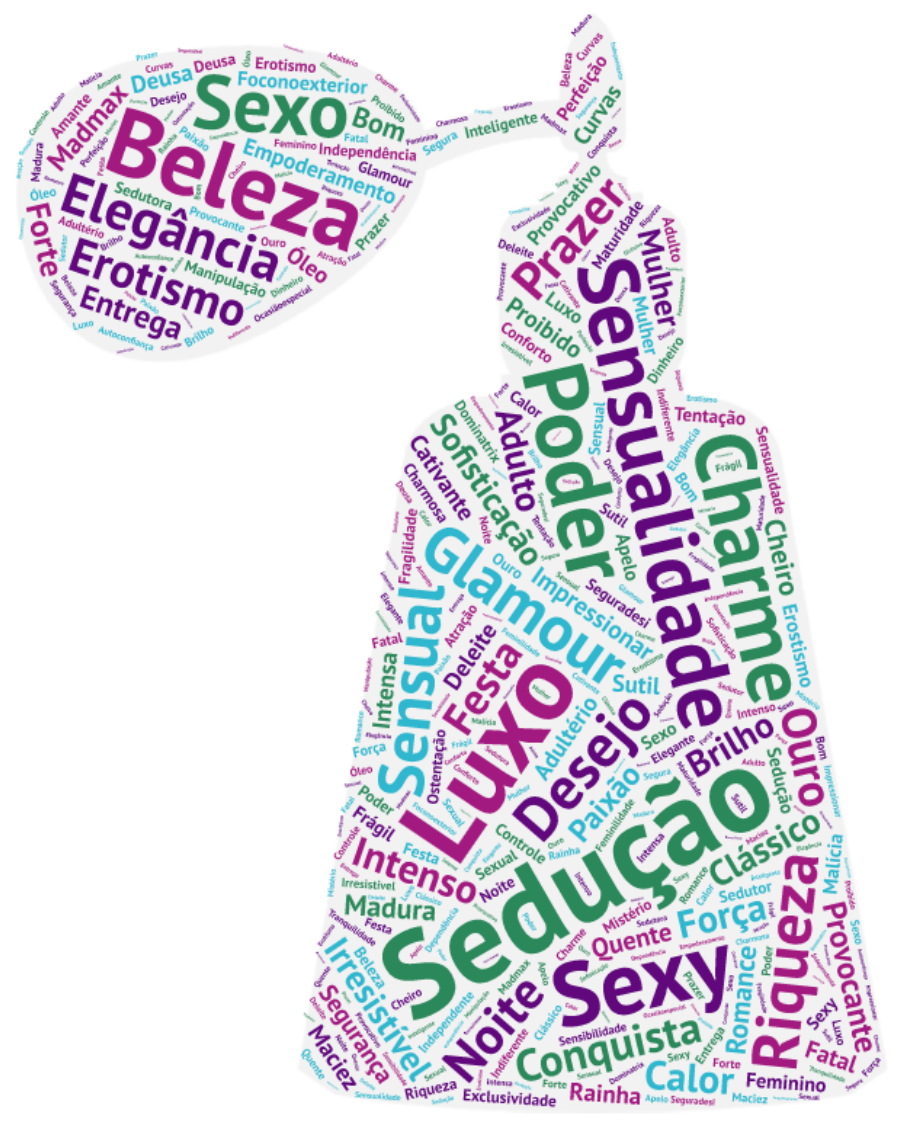

O anúncio do perfume J'adore surge como um símbolo tangível da sensualidade e da sedução. Ao esborrifar sua fragrância, metaforicamente, uma mulher poderá "exalar" todo o seu magnetismo. Os significados atribuídos ao perfume pela publicidade e pelo design gráfico do anúncio da marca Dior - verificados aqui por meio da pesquisa - serão transferidos, pelo o que indica o modelo do transito do significado de McCracken (2003), a uma possível consumidora do J'adore. Por meio da compra deste produto ela evocará e aflorará a mulher sedutora dentro de si; acionando todo o seu magnetismo e atratividade, materializando-a em sua identidade.

Como no trânsito do significado cultural os bens adquirem significados que são, posteriormente, atribuídos aos indivíduos, logo, quem comprar/consumir o J'adore ou o Miss Dior Chérie poderá evocar ou despertar aspectos subjetivos referentes a esses significados. 0 consumidor tangibiliza os padrões imateriais que foram concretizados nos perfumes da Dior. Obviamente, estamos nos baseando nas suposições levantadas pelas teorias discutidas nesta pesquisa. Para termos certezas mais efetivas, seriam necessárias novas etapas da pesquisa qualitativa; por exemplo, entrevistas em profundidade com consumidoras reais desses.

\section{Considerações finais}

O presente estudo descreveu, a partir de uma revisão de literatura, de que maneira o consumo pós-moderno vem atribuindo significados intangíveis às marcas, bens e serviços. De modo resumido, explicamos que, para atribuir e transferir tais significados, o sistema de consumo é mediado pelas estratégias comunicacionais das corporações como, por exemplo, o design gráfico e a publicidade. $O$ design gráfico, nesse contexto, organiza as expressões e informações visuais dos anúncios publicitários para que o consumidor reconheça a mensagem 
que se pretende transmitir e sinta a emoção que se pretende evocar. Assim, a composição de formatos, fotografias, tipografias e cores compõem os discursos simbólicos e tornam visíveis os significados intangíveis. Em suma, o design gráfico se ocupa da construção de mensagens visuais que afetam nossas subjetividades. Ele atua nas nossas emoções e ajuda-nos a darmos forma aos nossos sentimentos em relação ao mundo que nos cerca.

Verificamos essa hipótese por meio de uma pesquisa visual aplicada. Demonstramos como os participantes deram sentidos subjetivos as informações contidas em anúncios publicitários de perfumes femininos. Com os resultados da coleta de dados afirmamos que todos foram afetados pelas imagens. Logo, o estudo evidenciou que os anúncios publicitários, decorrentes dos projetos e das atividades de design gráfico, que controlam e organizam os elementos visuais perceptíveis, propiciaram sensações e impressões subjetivas cooperando com a lógica do consumo pós-moderno.

\section{Referências}

Barbosa, L. \& Campbell, C. (2006). Cultura, consumo e identidade. Rio de Janeiro: FGV.

Batey, M. (2010). O significado da marca: como as marcas ganham vida na mente dos consumidores. Rio de Janeiro: Best Business.

Birman, J. (2003). Freud e a filosofia. Rio de Janeiro: Jorge Zahar.

Canevacci, M. (2001). Antropologia da comunicação visual. Rio de Janeiro: DP\&A.

Collier, J. (1973). Antropologia visual: a fotografia como método de pesquisa. São Paulo: EPU.

Cunha, E. L. (2007). Uma leitura freudiana da categoria de identidade em Anthony Giddens. Ágora: estudos em teoria psicanalítica, (10)2, 171-186.

Frascara, J. (2001). Diseño gráfico para la gente: comunicaciones de masa y cambio social. Buenos Aires: Ediciones Infinito.

Gobé, M. (2010). Brandjam: o design emocional na humanização das marcas. Rio de Janeiro: Rocco.

Hollis, R. (2000) Design gráfico: uma história concisa. São Paulo: Martins Fontes.

Jr, L. A. \& Nojima, V. L. (2010). Retórica do Design Gráfico: da prática a teoria. São Paulo: Blucher.

Lipovetsky, G. (2007). O império do efêmero: a moda e seu destino nas sociedades modernas. São Paulo, Companhia das Letras.

Loizos, P. (2013). Pesquisa qualitativa com imagem e som: um manual prático (cap. 6, 137155). Petrópolis: Vozes.

Martins, J. S. (2007). A natureza emocional da marca: construção de marcas líderes. Rio de Janeiro: Campus.

McCracken, G. (2003). Cultura \& Consumo: novas abordagens ao caráter simbólico dos bens e atividades de consumo. Rio de Janeiro: Mauad.

Moraes, D. (2010). Metaprojeto: o design do design. São Paulo: Blucher.

Newark, Q. (2009). O que é design gráfico? Porto Alegre: Bookman.

Perassi, R. (2001). A visualidade das marcas institucionais e comerciais como campo de significação. Tese de doutorado. Pontifícia universidade Católica de São Paulo, São Paulo, SP, Brasil.

Perassi, R. (2015). Do ponto ao pixel: sintaxe gráfica no videodigital. Florianópolis: CCE/UFSC. 
Perez, C. (2016). Signos da marca: expressividade e sensorialidade. São Paulo: Cengage Learning.

Randazzo, S. (1997). A criação de mitos na publicidade: como os publicitários usam o poder do mito e do simbolismo para criar marcas. São Paulo: Rocco.

Santaella, L. (2016). Signos da marca: expressividade e sensorialidade (Prefácio). São Paulo: Cengage Learning.

Schmiegelow, S. S. (2016). Disseminação do conhecimento de moda na digital de marcas populares de vestuário e acessórios. Dissertação de mestrado. Universidade Federal de Santa Catarina, Florianópolis, SC, Brasil.

Semprini, A. (2010). A marca pós-moderna: poder e fragilidade da marca na sociedade contemporânea. São Paulo: Estação das Letras Editora.

Serroy, J \& Lipovetsky, G. (2015). A estetização do mundo: viver na era do capitalismo artista. São Paulo: Companhia das Letras.

Souza, F. M. (2018). Marcas, mitos e subjetividades: os arquétipos das deusas gregas expressos em imagens publicitárias contemporâneas. Dissertação de Mestrado, Universidade Federal de Santa Catarina, Florianópolis, SC, Brasil.

Tittoni, J. (2008). Psicologia e fotografia: experiências em intervenções fotográficas. Lisboa: Dom Quixote Editora

Zwirtes, A. M. \& Perassi, R. (2015). Mídia e design gráfico no processo de comunicação do evento cultural festival de dança de Joinville. Projética, (6)1, 151-162.

\section{Sobre o(a/s) autor(a/es)}

Felipe Machado de Souza, Doutorando, UFSC, Brasil <mazafelipe@gmail.com>

Francisco A. P. Fialho, Doutor, UFSC, Brasil <fapfialho@gmail.com> 